\title{
Patterns in weight reduction behaviour by weight status in schoolchildren
}

\author{
Colette Kelly*, Michal Molcho and Saoirse Nic Gabhainn \\ Health Promotion Research Centre, 12 Distillery Road, School of Health Sciences, National University of Ireland, \\ Galway, Galway, Republic of Ireland
}

Submitted 23 December 2008: Accepted 21 October 2009: First published online 27 November 2009

\begin{abstract}
Objective: To investigate the relationships between weight reduction behaviour among non-overweight schoolchildren and dietary habits, perception of health, well-being and health complaints.

Design: Analysis of the 2006 Health Behaviour in School-aged Children survey, a cross-sectional study involving schoolchildren aged 10-17 years.

Setting: Schools in the Republic of Ireland.

Results: The proportion of children ( $n$ 3599) engaged in weight reduction behaviour ('dieting' among non-overweight students) was $10 \cdot 3 \%$. Older children, females and those from higher social classes (SC) were more likely to report such behaviour. Non-overweight schoolchildren who reported weight reduction behaviour were less likely than those not engaged in such behaviour to frequently consume sweets, soft drinks, crisps and chips/fried potatoes (OR from 0.39 (95\% CI $0 \cdot 17,0 \cdot 89)$ to $0 \cdot 72(95 \%$ CI $0.53,0 \cdot 99))$; were more likely to consume diet soft drinks (OR 1.50 (95\% CI $1 \cdot 03,2 \cdot 18)$; and were more likely to miss breakfast during the week (OR $0.62(95 \%$ CI $0 \cdot 48,0 \cdot 80)$. The risk of subjective health complaints increased (OR from 1.47 (95\% CI $1 \cdot 13,1 \cdot 91)$ to 1.92 (95\% CI 1.48 , $2 \cdot 49)$ ); as did body dissatisfaction (OR 9.17 (95\% CI 6.99, 12.02)), while perception of health and well-being decreased (OR 0.47 (95\% CI 0.36, 0.61)) to 0.54 (95\% CI 0.41, 0.70)). All analyses were controlled for age, gender and SC.

Conclusions: Weight reduction behaviour among non-overweight schoolchildren is associated with considerable risk to physical health and emotional well-being. Since the risks associated with such behaviour varies by weight status, health professionals and researchers need to consider these issues in parallel.
\end{abstract}

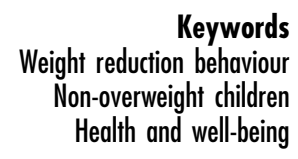

The increase in prevalence of obesity in children and adolescents is of major public health concern ${ }^{(1-4)}$. Obesity in childhood is associated with medical and psychosocial complications $^{(5)}$ and is likely to track into adulthood ${ }^{(2,5-7)}$. Prevention and intervention programmes for children have focused on family- and school-based initiatives, but long-term weight loss is difficult to achieve when adverse environmental factors overwhelm behavioural and educational techniques designed to modify diet and increase participation in physical activity ${ }^{(5)}$.

In light of the obesity epidemic, it is perhaps not surprising that dieting is such a prevalent behaviour among children $^{(8-11)}$ some of whom employ healthy dieting strategies to lose weight ${ }^{(9,12)}$. Self-reports of 'dieting' can, however, include unhealthy dietary practices and restrictive eating $^{(10,12,13)}$, with negative impacts on nutrient intakes ${ }^{(14)}$ and dieting often clusters with other risk behaviours ${ }^{(8,15,16)}$. There are also psychosocial risks associated with dieting, such as low self-esteem and depressive symptoms ${ }^{(8,16-19)}$. In addition, dieting is associated with weight gain ${ }^{(20-23)}$ and is also a risk factor for the development of a partial or full eating disorder ${ }^{(23-26)}$. The risks associated with dieting during childhood and adolescence, although normative, have led many to believe that it is not a harmless behaviour ${ }^{(20,22,25)}$.

Dieting is not confined to those who are overweight and obese, but is also prevalent among children who are not overweight and who are the focus of the current study $^{(8,27-35)}$. Indeed, perception of being overweight and body dissatisfaction, irrespective of weight status, are considered key factors in weight loss attempts ${ }^{(36)}$. Prevalence rates of dieting among non-overweight children vary between countries, which in part relates to the range of questions used to define dieting status, and the age range and time frame under investigation. In a crossnational study, current dieting among non-overweight girls ranged from 9\% (Netherlands) to $28 \%$ (Denmark) $^{(37)}$. Studies from Spain ${ }^{(38)}$ and Portugal (including boys) ${ }^{(33)}$ provide estimates of $4 \cdot 3 \%$ and $6 \%$, respectively. Rates among girls in the United States range from $30 \%^{(8)}$ to $42 \%{ }^{(29)}$; outside of the European Union and the United 
States estimates vary from $47 \%$ (Qatar) $^{(30)}$ to $38 \%$ (India) ${ }^{(32)}$ for dieting among non-overweight girls. Notably, the primary focus of these studies has been the behaviours of overweight participants, often employing the non-overweight group as a reference point ${ }^{(27,28)}$, or the behaviours of dieters in general ${ }^{(31,38,39)}$. Other studies, with data on non-overweight youth, explored eating disorder development among overweight children ${ }^{(27,38,40)}$ and among restrained eaters ${ }^{(29)}$.

Although dieting among non-overweight children is well recognised and the types of weight control practices employed by this group have been explored to some extent $^{(28,37,41)}$, the simultaneous investigation of diet and the context of eating, in addition to perception of health, emotional well-being and somatic symptoms among non-overweight dieting children, has not been reported. Therefore, the current study examined non-overweight schoolchildren who were attempting to lose weight, aged 10-17 years in Ireland, with the aim of exploring outcomes such as food habits and food-related behaviour, in addition to the risks of poor self-reported health, negative body image and subjective health complaints associated with weight-reduction behaviours.

\section{Methods}

\section{Sample}

The current study utilised data from the 2006 Irish Health Behaviour in School-aged Children study, a part of the WHO collaborative study (WHO-HBSC; www.hbsc.org). In the Republic of Ireland, children in primary (aged 10-12 years) and post-primary (12-18 years) schools were randomly selected, and individual classrooms within these schools were subsequently randomly selected for inclusion. The overall student response rate was $83 \%$. Ethical approval was obtained from the Research Ethics Committee of the National University of Ireland, Galway. Data on 3599 students are presented here, aged 10-17 years, in which self-reports of weight, height and demographic information were available.

\section{Measurement}

Data were collected using a self-completion questionnaire, administered by teachers, which was designed as part of the WHO-HBSC study involving researchers from all countries (www.hbsc.org).

To identify participants who were trying to lose weight, students were asked 'At present are you on a diet or doing something else to lose weight?', with response options 'Yes', 'No, because I need to put on weight', 'No, but I should lose some weight' and 'No, my weight is fine'. Students who answered yes were defined as 'those engaged in weight reduction behaviour' and the remainder as those not engaged in weight loss attempts in the current study.
Perceived body image was assessed by the question: 'Do you think your body is ...? Much too thin; A bit too thin; About the right size; A bit too fat; Much too fat'. Body dissatisfaction was categorised as 'a bit' and 'much too fat'. Adequate validity and reliability of the weight reduction and body image questions have been reported ${ }^{(42)}$.

Information on height and weight were collected by asking, 'How much do you weigh without clothes?' and 'How tall are you without shoes?' which was used to calculate BMI $\left(\mathrm{kg} / \mathrm{m}^{2}\right)$ and which are considered reliable for population studies ${ }^{(43)}$. Students' weight status was categorised by cut-offs corresponding to the international age- and gender-specific BMI reference values defined by Cole et $a l^{(44)}$ In the current study, the group of overweight adolescents includes those who are obese.

Students were asked how often they usually eat or drink the following items: fruit, vegetables, sweets, soft drinks, crisps, chips/fried potatoes and fish. They were provided with a seven-point scale with the following response options: 'never', 'less than once a week', 'once a week', '2-4 days a week', '5-6 days a week', 'once a day, every day' and 'every day more than once'. Fruit and vegetable variables were dichotomised into more than once daily $v$. daily or less. Fish was dichotomised into weekly $v$. less than weekly and the remaining food variables into daily $v$. less than daily.

To assess weekday breakfast consumption, adolescents were asked to indicate how many days in a week they had breakfast (defined as 'more than a glass of milk or fruit juice'). There were six response categories: 'never', '1 day', '2 days', '3 days', '4 days' and '5 days'. The responses were dichotomised into 'daily breakfast consumption' $v$. 'less than daily'.

Students were asked how often do you 'have breakfast together with your mother or father?', 'have an evening meal together with your mother or father?', 'eat a snack whilst you watch television (TV; including videos and DVDs)?', 'eat a snack while you work or play on a computer or games console?' and 'watch TV while having a meal?' Response options were 'never', 'less than once a week', '1-2 days a week', '3-4 days a week', '5-6 days a week' and 'every day'. Responses were categorised as daily $v$. less than daily. The validity of the food frequency questions, the breakfast item and food-related lifestyle questions have been reported previously ${ }^{(45-47)}$.

Self-rated health was assessed by the question 'Would you say your health is?' and the response options were dichotomised at excellent $v$. good, fair or poor. Self-reported happiness was measured by the question 'In general, how do you feel about your life at present?' and the responses were dichotomised at very happy $v$. quite happy, don't feel very happy and not happy at all. Children were also asked to rank themselves from 0 to 10 on a life satisfaction ladder ${ }^{(48)}$. This scale was used to identify those with high life satisfaction (response $>7$ ). 
Table 1 Sociodemographic characteristics of respondents by weight reduction behaviour ('dieting') and weight status

\begin{tabular}{|c|c|c|c|c|c|c|}
\hline & \multicolumn{2}{|c|}{ All } & \multicolumn{2}{|c|}{ Non-overweight } & \multicolumn{2}{|c|}{ Overweight and obese } \\
\hline & $\begin{array}{l}\text { Dieting } \\
(n \text { 455) }\end{array}$ & $\begin{array}{l}\text { Not dieting } \\
(n 3144)\end{array}$ & $\begin{array}{l}\text { Dieting } \\
(n \text { 319) }\end{array}$ & $\begin{array}{l}\text { Not dieting } \\
(n \text { 2777) }\end{array}$ & $\begin{array}{l}\text { Dieting } \\
(n \text { 136) }\end{array}$ & $\begin{array}{l}\text { Not dieting } \\
\quad(n 367)\end{array}$ \\
\hline \multicolumn{7}{|l|}{ Age (years) } \\
\hline Mean & $14 \cdot 8$ & $14 \cdot 5$ & $14 \cdot 9$ & $14 \cdot 5$ & $14 \cdot 7$ & $14 \cdot 5$ \\
\hline $\mathrm{SD}$ & $1 \cdot 44$ & 1.56 & $1 \cdot 41$ & 1.56 & $1 \cdot 50$ & $1 \cdot 62$ \\
\hline Male (\%) & $87 \cdot 2$ & $23 \cdot 5$ & $35 \cdot 7$ & $58 \cdot 4$ & $51 \cdot 5$ & $65 \cdot 1$ \\
\hline Female (\%) & $12 \cdot 8$ & $76 \cdot 5$ & $64 \cdot 3$ & $41 \cdot 6$ & $48 \cdot 5$ & $34 \cdot 9$ \\
\hline Age $10-11$ years (\%) & $10 \cdot 6$ & $18 \cdot 0$ & $4 \cdot 7$ & $7 \cdot 6$ & $5 \cdot 9$ & $10 \cdot 4$ \\
\hline Age $12-14$ years (\%) & $90 \cdot 1$ & $92 \cdot 0$ & $40 \cdot 8$ & $46 \cdot 8$ & $49 \cdot 3$ & $45 \cdot 2$ \\
\hline Age $15-17$ years $(\%)$ & $99 \cdot 4$ & $90 \cdot 0$ & $54 \cdot 5$ & $45 \cdot 6$ & 44.9 & $44 \cdot 4$ \\
\hline High social class (\%) & $65 \cdot 2$ & 63.9 & $41 \cdot 4$ & $34 \cdot 8$ & $23 \cdot 8$ & $29 \cdot 1$ \\
\hline Medium social class (\%) & $95 \cdot 8$ & $94 \cdot 2$ & $41 \cdot 8$ & 43.9 & $54 \cdot 0$ & $50 \cdot 3$ \\
\hline Low social class (\%) & $39 \cdot 0$ & 41.9 & $16 \cdot 8$ & $21 \cdot 3$ & $22 \cdot 2$ & $20 \cdot 6$ \\
\hline
\end{tabular}

Subjective health complaints were assessed by asking children to report the frequency, in the 6 months before the survey, that they experienced a variety of emotional (feeling low) and physical symptoms (headache, stomach ache). Response options were 'about every day', 'more than once a week', 'about every week', 'about every month' and 'rarely or never'. Responses were categorised at weekly or more $v$. less often. Items within the scale have shown an adequate content validity and test-retest reliability $^{(49)}$.

Children were also asked to report the occupation of their parents through which a three-category social class (SC) scale was created using the UK Registrar General's classification of occupations ${ }^{(50)}$. SC was defined as high (SC 1 and 2), medium (SC 3 and 4) and low (SC 5 and 6).

\section{Statistical analyses}

Associations between weight reduction behaviour among non-overweight children ('dieting' among non-overweight children) and the outcome measures are expressed in OR from logistic regression models in the Statistical Package for the Social Sciences statistical software package version 15.0 (SPSS Inc., Chicago, IL, USA). All analyses were controlled for age, gender and SC, and were conducted separately for those who were not overweight, overweight and obese and the group as a whole. The reference group was the group of children who were not attempting to lose weight.

\section{Results}

The current study presents data from 3599 children, $12.6 \%$ of whom report that they are currently on a diet or doing something to lose weight. The percentage of girls who are engaged in weight reduction behaviour increases with age, from $7 \cdot 8 \%$ of $10-11$-year-olds to $21.7 \%$ of $15-17$-year-olds, whereas the percentage of boys engaged in such behaviour remains relatively stable across age groups $(9 \cdot 2 \%$ of $10-11$-year-olds to $8 \cdot 2 \%$ of 15-17-year-olds).

Among non-overweight students, $10 \cdot 3 \%$ are currently engaged in weight reduction behaviours. Table 1 presents the children's sociodemographic characteristics broken down by BMI and dieting status. Those who are not overweight and engaged in weight reduction behaviour are older $(P<0 \cdot 01)$, more likely to be girls $(P<0 \cdot 001)$, and from higher SC $(P<0 \cdot 05)$. Those who are overweight and employing weight reduction behaviour are more likely to be male $(P<0 \cdot 01)$ with no clear age or SC patterns.

Among non-overweight children, weight reduction behaviour was significantly associated with less frequent consumption of sweets, soft drinks, crisps and chips/fried potatoes and with more frequent consumption of diet soft drinks (Table 2). This group of children were less likely to have breakfast during the week than those not engaged in weight reduction behaviour within this BMI category, with adjusted OR of 0.62 (95\% CI $0 \cdot 48,0 \cdot 80$ ). Although there was a trend for not having family meals together, this was not statistically significant.

Engaging in weight reduction behaviour among nonoverweight children was also found to be significantly associated with frequent headaches, stomach aches and reports of feeling low (Table 2). These children were significantly more likely to feel dissatisfied with their life and were less likely to report that they feel very happy. Perception of their health was poor with adjusted OR of 0.50 (95\% CI 0.37, 0.66). Body dissatisfaction, defined as feeling a little or too much fat, was positively associated with weight reduction behaviour with adjusted OR of $9 \cdot 17$ (95\% CI $6.99,12 \cdot 02)$. Corresponding figures for the group as a whole and the overweight group were $7 \cdot 85$ (95\% CI 6 13 , $10 \cdot 05)$ and $3 \cdot 48$ (95\% CI 2.03, 5.97), respectively. Gender differences in these patterns were explored by stratifying analyses; no consistent or substantial differences were identified, with two exceptions; the odds for girls engaged in weight reduction behaviour to report high life satisfaction and happiness were lower than those for boys, whereas girls engaged in weight reduction behaviour had higher odds for subjective health complaints than boys. 
Table 2 Adjusted relative odds of food habits, meal habits, health and well-being perceptions, subjective health complaints and body dissatisfaction by weight status

\begin{tabular}{|c|c|c|c|c|c|c|}
\hline & \multicolumn{2}{|c|}{ All ( $n$ 3599) } & \multicolumn{2}{|c|}{$\begin{array}{l}\text { Overweight and obese } \\
\qquad(n 503)\end{array}$} & \multicolumn{2}{|c|}{$\begin{array}{l}\text { Non-overweight } \\
\quad(n \text { 3096) }\end{array}$} \\
\hline & Adj ORt & $95 \% \mathrm{Cl}$ & Adj ORt & $95 \% \mathrm{Cl}$ & Adj ORt & $95 \% \mathrm{Cl}$ \\
\hline \multicolumn{7}{|l|}{ Diet } \\
\hline Fruit $>$ daily & 0.98 & $0 \cdot 76,1.27$ & $1 \cdot 42$ & $0 \cdot 86,2 \cdot 37$ & $0 \cdot 87$ & $0 \cdot 64,1 \cdot 18$ \\
\hline Vegetables $>$ daily & 0.96 & $0 \cdot 74,1 \cdot 26$ & $1 \cdot 18$ & $0 \cdot 69,2 \cdot 00$ & 0.91 & $0 \cdot 67,1 \cdot 25$ \\
\hline Sweets at least daily & $0.57^{\star \star \star}$ & $0.45,0.72$ & $0 \cdot 44^{\star *}$ & $0 \cdot 27,0.72$ & $0 \cdot 61^{\star \star *}$ & $0 \cdot 47,0 \cdot 80$ \\
\hline Soft drinks at least daily & $0 \cdot 63^{\star \star}$ & $0.48,0.83$ & $0 \cdot 41^{\star \star}$ & $0 \cdot 23,0.71$ & $0 \cdot 72^{\star}$ & $0.53,0.99$ \\
\hline Diet soft drinks at least daily & $1 \cdot 44^{*}$ & $1 \cdot 04,2 \cdot 00$ & $1 \cdot 24$ & $0 \cdot 65,2 \cdot 36$ & $1 \cdot 50^{*}$ & $1 \cdot 03,2 \cdot 18$ \\
\hline Crisps at least daily & $0 \cdot 49^{\star \star *}$ & $0 \cdot 34,0.72$ & $0 \cdot 34^{* *}$ & $0 \cdot 16,0 \cdot 72$ & $0.57^{\star}$ & $0 \cdot 37,0 \cdot 87$ \\
\hline Chips/fried potatoes at least daily & $0 \cdot 36^{\star \star}$ & $0 \cdot 18,0 \cdot 71$ & $0 \cdot 29^{*}$ & $0.08,0.99$ & $0 \cdot 39^{*}$ & $0 \cdot 17,0.89$ \\
\hline Fish at least weekly & $1 \cdot 08$ & $0 \cdot 87,1 \cdot 33$ & $1 \cdot 29$ & $0.84,1.99$ & 0.98 & $0 \cdot 77,1 \cdot 26$ \\
\hline \multicolumn{7}{|l|}{ Meal habits } \\
\hline Breakfast every weekday & $0 \cdot 74^{\star}$ & $0.55,0.99$ & $1 \cdot 75$ & $0.92,3.36$ & $0 \cdot 62^{\star \star \star}$ & $0.48,0 \cdot 80$ \\
\hline Breakfast with mother/father every day & $0 \cdot 80$ & $0.59,1.08$ & $0 \cdot 85$ & $0.46,1.58$ & 0.82 & $0 \cdot 57,1 \cdot 16$ \\
\hline Evening meal with mother/father every day & $0 \cdot 80^{*}$ & $0.65,0.97$ & 0.85 & $0.56,1 \cdot 30$ & $0 \cdot 81$ & $0 \cdot 63,1 \cdot 04$ \\
\hline Snack while watching television every day & 0.93 & $0 \cdot 72,1 \cdot 20$ & $0.56^{*}$ & $0.32,0.97$ & $1 \cdot 06$ & $0 \cdot 79,1 \cdot 41$ \\
\hline Snack while on computer/games console every day & 0.68 & $0.43,1.07$ & $0 \cdot 47$ & $0 \cdot 19,1 \cdot 17$ & $0 \cdot 79$ & $0 \cdot 47,1 \cdot 33$ \\
\hline Meal while watch television every day & $1 \cdot 12$ & $0 \cdot 86,1 \cdot 46$ & 0.94 & $0.57,1.54$ & $1 \cdot 18$ & $0.86,1.62$ \\
\hline \multicolumn{7}{|l|}{ Health and well-being perception } \\
\hline Excellent self-rated health & $0 \cdot 50^{\star * *}$ & $0.39,0.65$ & $0.57^{*}$ & $0.33,0.98$ & $0 \cdot 50^{\star \star \star}$ & $0.37,0.66$ \\
\hline High life satisfaction & $0 \cdot 56^{\star \star \star}$ & $0 \cdot 44,0 \cdot 70$ & 0.65 & $0.41,1.02$ & $0 \cdot 54^{\star * *}$ & $0.41,0.70$ \\
\hline Feel very happy about life & $0 \cdot 49^{\star \star \star}$ & $0.39,0.62$ & $0 \cdot 71$ & $0 \cdot 40,1 \cdot 24$ & $0 \cdot 47^{\star \star \star}$ & $0.36,0.61$ \\
\hline \multicolumn{7}{|l|}{ Subjective health complaints } \\
\hline Headache weekly or more & $1 \cdot 53^{\star \star \star}$ & $1 \cdot 22,1 \cdot 91$ & $1 \cdot 59^{*}$ & $1 \cdot 01,2 \cdot 50$ & $1 \cdot 47^{\star \star}$ & $1 \cdot 13,1.91$ \\
\hline Stomach ache weekly or more & $1 \cdot 71^{\star \star \star}$ & $1 \cdot 31,2 \cdot 22$ & $1 \cdot 67$ & $0.96,2.93$ & $1 \cdot 70^{\star \star}$ & $1 \cdot 26,2 \cdot 30$ \\
\hline Feeling low weekly or more & $1 \cdot 71^{\star \star *}$ & $1 \cdot 36,2 \cdot 14$ & $1 \cdot 15$ & $0 \cdot 74,1 \cdot 79$ & $1 \cdot 92^{\star \star \star}$ & $1 \cdot 48,2 \cdot 49$ \\
\hline \multicolumn{7}{|l|}{ Body dissatisfaction } \\
\hline Feel a little or much too fat & $7 \cdot 85^{\star \star \star}$ & $6 \cdot 13,10 \cdot 05$ & $3 \cdot 48^{\star \star *}$ & $2 \cdot 03,5 \cdot 97$ & $9 \cdot 17^{\star \star \star}$ & $6 \cdot 99,12 \cdot 02$ \\
\hline
\end{tabular}

Reference group: those not engaged in weight reduction behaviour.

Odds ratio was significant: ${ }^{\star} P<0 \cdot 05,{ }^{\star \star} P<0.01 ;{ }^{\star * \star} P<0.001$.

tAdjusted OR, adjusted for age, gender and social class.

One-way analysis of covariance, controlling for age, gender and SC were conducted with all dependent variables listed in Table 2. Significant differences emerged between overweight/obese and non-overweight 'dieters' on two dependent variables; 'dieters' who were overweight/ obese were less likely to report snacking while watching TV every day than those who were non-overweight $(F=3.89 ; \mathrm{df}=1.423 ; P<0.05)$, and were more likely to report feeling a little or too much fat $(F=19 \cdot 05$; $\mathrm{df}=$ 1.420; $P<0 \cdot 001)$.

\section{Discussion}

Dieting is now considered normative among adolescents, which increases the need to investigate the various weight control strategies employed and psychosocial risks associated with dieting, by BMI status. To date, fewer analyses have focused on non-overweight children engaged in dieting for whom dieting may be associated with different risks than those who are overweight and dieting. The current study aimed to explore weight reduction behaviour among non-overweight schoolchildren in Ireland, investigating diet and family meal habits, but with a particular focus on subjective health complaints, perceived health, life satisfaction and happiness.

\section{Weight reduction bebaviour among non- overweight schoolchildren}

The current study illustrates the extent of weight reduction behaviour among non-overweight schoolchildren; $10 \cdot 3 \%$ of children who are not overweight are currently attempting to lose weight. It is difficult to compare the extent of this problem to other studies due to methodological differences, but this is the first study to report this phenomenon among primary and post-primary schoolchildren in Ireland. In a cross-national survey conducted in 2001-2002 that included 13- and 15-year-old children, rates of current dieting to lose weight among nonoverweight girls and boys in Ireland were 20 and $4 \%$, respectively ${ }^{(37)}$. The difference between these two studies is likely to reflect the increase in prevalence of dieting with age among girls. Non-overweight girls were reporting weight reduction behaviour more often than boys in the current study, which is consistent with the literature ${ }^{(18,37,40)}$. More children from higher SC were engaged in such behaviours compared to those from lower SC, and although there is evidence that diet quality follows a socio-economic gradient ${ }^{51)}$, there appears to be inconsistency around the relationship between 'dieting' in general and SC. No clear consistent relationship between family affluence and dieting across countries ${ }^{(11)}$, or between dieting and $\mathrm{SC}^{(14)}$, have been reported for the children. 
However, others have reported a positive association between dieting and SC among 18-year-old college female students ${ }^{(52)}$. The current study appears to be the first report of a positive relationship between weight control behaviour and SC among non-overweight children.

\section{Diet and meal babits}

Non-overweight children who are trying to lose weight are not eating more health-promoting foods, such as fruit, vegetables and fish, but do report eating less highfat, sugar-containing snack foods. Food choice of such 'dieters' has not been the focus of earlier work, unlike studies of overweight children and dieters per se, and so this finding is important to document. It is, however, consistent with reports of poor food choice among adolescent dieters generally ${ }^{(10,14)}$, including children in Ireland who are dieting ${ }^{(15)}$.

Breakfast skipping was also prevalent among nonoverweight 'dieters', which is consistent with the literature on weight loss practices employed by children generally ${ }^{(35)}$. This tends to result in an overall poorer quality diet ${ }^{(53-56)}$, coupled with the fact that these children are not eating more fruit, vegetables or fish, suggests that these children are at risk of nutritional inadequacies. The association between breakfast consumption and cognitive function at school ${ }^{(56)}$ also suggests that these children may be at a disadvantage in terms of their participation at school.

Daily family meals (i.e. breakfast and evening meals) were found to be less common among non-overweight 'dieters' compared with 'non-dieters'. Regular family meal times are associated with more healthful diets of children and adolescents ${ }^{(57-60)}$. Eating together is also an opportunity for parents to act as a model for healthy eating ${ }^{(61-63)}$, to have discussions about food and health ${ }^{(57)}$ and to contribute to the development of 'regular' meal patterns, all of which may also help the positive psychosocial development of children and adolescents ${ }^{(60)}$. Although the protective role of family meals against disordered eating among adolescents has been identified ${ }^{(64)}$, the reasons for less frequent family meals among nonoverweight children who are engaged in attempts at weight loss has not been explored to date. It is possible that family structure, organisation within the family, communication and connectedness may influence the frequency and nature of family meals and may also pose as potential barriers to habitual family meal times.

\section{Subjective bealth complaints}

Somatic symptoms, such as stomach ache and headache, and psychological symptoms, such as 'feeling low', were more likely to be reported by non-overweight 'dieters'. These psychosomatic symptoms can place an immense burden on the individual ${ }^{(65)}$ and can, in some cases, also impact on the health-care system ${ }^{(66,67)}$. In most cases, it is thought that the presentation of such symptoms reflects not an organic disorder but an imbalance between the increasing educational, social, and perhaps sporting, demands on children and physiological 'debts' owed to rapid growth and sexual development ${ }^{(68)}$. For this particular group, attempts at weight loss may present an additional 'stress' or demand. Subjective health complaints such as poor self-esteem, depressive symptoms ${ }^{(8,16,17)}$, increased irritability, problems with concentration and sleep disturbances ${ }^{(18)}$ have been associated with dieting, but the prevalence of somatic symptoms such as headaches and stomach aches among dieters has not been reported in the literature. It could be hypothesised that weight loss attempts may increase the likelihood of stomach aches, headaches and feeling low, with hunger playing a dominant role. The likelihood of 'feeling low' could also be increased by the desire, and perhaps the failure, to reach the thin ideal under pursuit.

\section{Perceptions of bealth and well-being}

The likelihood of reporting high life satisfaction, happiness and excellent self-rated health was decreased among non-overweight children who were 'dieting', but whether this is as a direct result of dieting or adolescence more generally could not be deduced from these analyses. Nevertheless, children who are of normal weight and are engaged in 'dieting' tend to be more unhappy and rate their health and satisfaction with life poorly. Interventions that could improve these outcomes are likely to have positive influences on health behaviours generally, including engaging in dieting.

\section{Body dissatisfaction}

There was a strong positive association between weight reduction behaviour among non-overweight schoolchildren and body dissatisfaction. This is consistent with earlier work showing that body dissatisfaction is associated with dieting and unhealthy weight control behaviours, irrespective of weight status ${ }^{(36)}$. Studies indicate that between 25 and $80 \%$ of adolescent girls report significant body dissatisfaction ${ }^{(69)}$, with $59 \%$ of 15 -year-old girls from an urban city in Ireland expressing a desire to be thinner. Elevated perceived pressure to be thin, thinideal internalisation and body mass are the main risk factors for body dissatisfaction ${ }^{(70)}$. Socio-cultural pressures to be thin from the mass media ${ }^{(71-73)}$, and the role of the family ${ }^{(74)}$ and friends on body satisfaction ${ }^{(75-77)}$, have been documented previously. The current study illustrates that non-overweight 'dieters' are at an elevated risk of body dissatisfaction; yet despite work to date, the best approach to fostering a positive body image among children remains unclear. Future work could explore the impact of body dissatisfaction.

One limitation of the current study is the cross-sectional design, making it impossible to determine causality or to differentiate a precursor of weight loss attempts among non-overweight children from a consequence for any of the relationships described. Another potential limitation 
includes reliance on self-report for the variables under investigation. However, students' responses were anonymous; therefore, participants had no reason to misreport their responses. BMI based on self-reported data can produce lower prevalence estimates of overweight than those based on objective measurements, both among adults $^{(78)}$ and adolescents ${ }^{(79)}$. Others have reported high accuracy for classification of youth as obese or non-obese based on self-reported data ${ }^{(43)}$, and BMI based on selfreports has been found to be fairly reliable and suitable for identifying valid relationships in epidemiological studies ${ }^{(43)}$. Strengths include the large sample size and inclusion of children at a national level. All measurements have also been piloted and tested before administration to the children.

\section{Conclusion}

In adolescence, the need for a diet of high nutritional quality is paramount, given the physiological changes taking place and the emotional challenges young people face. An unbalanced diet can result in obesity or indeed undernutrition. Although obesity has received considerable attention as a major public health challenge, dieting in young people is perhaps perceived as less of a problem. One of the possible reasons is that dieting is considered a normative behaviour in children, despite the documented risks associated with it. Second, the challenge of identifying and working with those who are dieting currently lies with the dietetic profession. However, this report and others suggest that 'dieting' among non-overweight children requires the attention of various health professionals and not dietitians alone. Frequent somatic symptoms and poor emotional well-being will ultimately affect primary care, schools and families. Thus, the need to highlight weight reduction behaviours among non-overweight schoolchildren as a public health problem is paramount. Families and schools are most likely to observe the consequences of dieting and may be the very avenues that can help with identification and addressing such challenges.

\section{Acknowledgements}

The current study was funded by the Department of Health and Children, Ireland. There are no conflicts of interest. C.K. participated in the design and data collection for the study and drafted the manuscript. M.M. participated in the design and data collection for the study and edited the manuscript. S.N.G. participated in the design and data collected for the study, conceived of the study questions, performed the statistical analysis and edited the manuscript. All authors have read and approved the final manuscript. We acknowledge all the parents and children who consented and participated, as well as the management authorities, principals and teachers in all schools who participated. HBSC is an international study carried out in collaboration with WHO/EURO. The international coordinator of HBSC is Professor Candace Currie (University of Edinburgh) and the data bank manager is Dr Oddrun Samdal (University of Bergen). For details, see http://www.hbsc.org/

\section{References}

1. Bundred P, Kitchiner D \& Buchan I (2001) Prevalence of overweight and obese children between 1989 and 1998: population based series of cross sectional studies. BMJ 322, 326-328.

2. Dietz WH (2004) Overweight in childhood and adolescence. $N$ Engl J Med 350, 855-857.

3. Lobstein TJ, James WPT \& Cole TJ (2003) Increasing levels of excess weight among children in England. Int J Obes 27, $1136-1138$.

4. Ogden C, Flegal K, Carroll M et al. (2002) Prevalence and trends in overweight among US children and adolescents, 1999-2000. JAMA 288, 1728-1732.

5. Ebbeling CB, Pawlak DB \& Ludwig DS (2002) Childhood obesity: public-health crisis, common sense cure. Lancet 360, 473-482.

6. Freedman DS, Khan LK, Serdula MK et al. (2005) The relation of childhood BMI to adult adiposity: the Bogalusa Heart Study. Pediatrics 115, 22-27.

7. Guo SS \& Chumlea WC (1999) Tracking of body mass index in children in relation to overweight in adulthood. Am J Clin Nutr 70, 145S-148S.

8. Crow S, Eisenberg ME, Story M et al. (2006) Psychosocial and behavioral correlates of dieting among overweight and non-overweight adolescents. J Adolesc Health 38, 569-574.

9. Eaton DK, Kann L, Kinchen S et al. (2008) Youth risk behavior surveillance - United States, 2007. Surveillance summaries. MMWR 57, 1-131.

10. Nowak M (1998) The weight-conscious adolescent: body image, food intake, and weight-related behavior. $J$ Adolesc Health 23, 389-398.

11. Currie C, Nic Gabhainn S, Godeau E et al. (2008) Inequalities in Young People's Health: International Report from the HBSC 2005/O6 Survey. WHO Policy Series: Health Policy for Children and Adolescents no. 5. Copenhagen: WHO Regional Office for Europe.

12. Neumark-Sztainer D, Hannan PJ, Story M et al. (2004) Weight-control behaviors among adolescent girls and boys: implications for dietary intake. J Am Diet Assoc 104, 913-920.

13. Middleman AB, Vazquez I \& Durant RH (1998) Eating patterns, physical activity, and attempts to change weight among adolescents. $J$ Adolesc Health 22, 37-42.

14. Neumark-Sztainer D, Rock CL, Thornquist MD et al. (2000) Weight-control behaviors among adults and adolescents: associations with dietary intake. Prev Med 30, 381-391.

15. Nic Gabhainn S, Nolan G, Kelleher C et al. (2002) Dieting patterns and related lifestyles of school-aged children in the Republic of Ireland. Public Health Nutr 5, 457-462.

16. French SA, Story M, Downes B et al. (1995) Frequent dieting among adolescents: psychosocial and health behavior correlates. Am J Public Health 85, 695-701.

17. Neumark-Sztainer D \& Hannan PJ (2000) Weight-related behaviors among adolescent girls and boys: results from a national survey. Arch Pediatr Adolesc Med 154, 569-577.

18. Pesa J (1999) Psychosocial factors associated with dieting behaviors among female adolescents. J Sch Health 69, 196-201. 
19. Canpolat BI, Orsel S, Akdemir A et al. (2005) The relationship between dieting and body image, body ideal, self-perception, and body mass index in Turkish adolescents. Int J Eat Disord 37, 150-155.

20. Field AE, Austin SB, Taylor CB et al. (2003) Relation between dieting and weight change among preadolescents and adolescents. Pediatrics 112, 900-906.

21. Cannon G (2005) Dieting. Makes you fat? Br J Nutr 93 , 569-570.

22. Stice E, Cameron RP, Killen JD et al. (1999) Naturalistic weight-reduction efforts prospectively predict growth in relative weight and onset of obesity among female adolescents. J Consult Clin Psychol 67, 967-974.

23. Neumark-Sztainer D, Wall M, Guo J et al. (2006) Obesity, disordered eating, and eating disorders in a longitudinal study of adolescents: how do dieters fare 5 years later? $\mathrm{J} \mathrm{Am}$ Diet Assoc 106, 559-568.

24. Spear BA (2006) Does dieting increase the risk for obesity and eating disorders? J Am Diet Assoc 106, 523-525.

25. Patton GC, Selzer R, Coffey C et al. (1999) Onset of adolescent eating disorders: population based cohort study over 3 years. BMJ 318, 765-768.

26. Chamay-Weber C, Narring F \& Michaud P-A (2005) Partial eating disorders among adolescents: a review. J Adolesc Health 37, 416-426.

27. Vander Wal JS (2004) Eating and body image concerns among average-weight and obese African American and Hispanic girls. Eat Behav 5, 181-187.

28. Boutelle K, Neumark-Sztainer D, Story M et al. (2002) Weight control behaviors among obese, overweight, and nonoverweight adolescents. J Pediatr Psychol 27, 531-540.

29. French SA, Perry CL, Leon GR et al. (1995) Dieting behaviours and weight change history in female adolescents. Health Psychol 14, 548-555.

30. Bener A \& Tewfik I (2006) Prevalence of overweight, obesity, and associated psychological problems in Qatari's female population. Obes Rev 7, 139-145.

31. Koff E \& Rierdan J (1991) Perceptions of weight and attitudes toward eating in early adolescent girls. J Adolesc Health 12, 307-312.

32. Chugh R \& Puri S (2001) Affluent adolescent girls of Delhi: eating and weight concerns. Br J Nutr 86, 535 .

33. Fonseca H \& Gaspar de Matos M (2005) Perception of overweight and obesity among Portuguese adolescents: an overview of associated factors. Eur J Public Health 15, 323-328.

34. Patton GC, Carlin JB, Shao Q et al. (1997) Adolescent dieting: healthy weight control or borderline eating disorder? J Child Psychol Psychiatry 38, 299-306.

35. Strauss RS (1999) Self-reported weight status and dieting in a cross-sectional sample of young adolescents: National Health and Nutrition Examination Survey III. Arch Pediatr Adolesc Med 153, 741-747.

36. Neumark-Sztainer D, Paxton SJ, Hannan PJ et al. (2006) Does body satisfaction matter? Five-year longitudinal associations between body satisfaction and health behaviors in adolescent females and males. $J$ Adolesc Health 39, 244-251.

37. Ojala K, Vereecken C, Valimaa R et al. (2007) Attempts to lose weight among overweight and non-overweight adolescents: a cross-national survey. Int J Behav Nutr Phys Act 4, 50.

38. López-Guimerà G, Fauquet J, Portell M et al. (2008) Dieting in Spanish adolescent girls. Eur Eat Disord Rev 16, 234-240.

39. Brugman E, Meulmeester JF, Spee-van der Wekke A et al. (1997) Dieting, weight and health in adolescents in The Netherlands. Int J Obes Relat Metab Disord 21, 54-60.

40. Vander Wal JS \& Thelen MH (2000) Eating and body image concerns among obese and average-weight children. Addict Behav 25, 775-778.

41. Neumark-Sztainer D, Story M, Hannan PJ et al. (2002) Weight-related concerns and behaviors among overweight and nonoverweight adolescents: implications for preventing weight-related disorders. Arch Pediatr Adolesc Med 156, 171-178.

42. Nemeth A \& Ojala K (2006) Body image and weight control behaviour. In Health Behaviour in School-aged Children: A WHO Cross-national Study, Research Protocol for the 2005/ O6 Survey, pp. 1-14 [C Currie, O Samdal, W Boyce et al., editors]. Edinburgh: University of Edinburgh.

43. Strauss RS (1999b) Validity of self-reported weight and height in young adolescents. Int J Obes Relat Metab Disord 23, 904-908.

44. Cole TJ, Bellizzi MC, Flegal KM et al. (2000) Establishing a standard definition for child overweight and obesity worldwide: international survey. BMJ 320, 1240-1243.

45. Vereecken C \& Maes L (2003) A Belgian study on the reliability and relative validity of the health behaviour in school-aged children food frequency questionnaire. Public Health Nutr 6, 581-588.

46. Vereecken C, De Henauw S \& Maes L (2005) Adolescents' food habits: results of the Health Behaviour in School-aged Children survey. Br J Nutr 94, 423-431.

47. Vereecken C, Rossi S, Giacchi MV et al. (2008) Comparison of a short food-frequency questionnaire and derived indices with a seven-day diet record in Belgian and Italian children. Int J Public Health 53, 297-305.

48. Cantril H (1965) The Pattern of Human Concerns. New Brunswick: Rutgers University Press.

49. Haughland S \& Wold B (2001) Subjective health complaints in adolescence-reliability and validity of survey methods. J Adolesc 24, 611-624.

50. Registrar General (1980) Classification of Occupations 1980. London: HM Stationery Office.

51. Darmon N \& Drewnowski A (2008) Does social class predict diet quality? Am J Clin Nutr 87, 1107-1117.

52. Drewnowski A, Kurth C \& Krahn D (1994) Body weight and dieting in adolescence: impact of socioeconomic status. Int J Eat Disord 16, 61-65.

53. Matthys C, De Henauw S, Bellernans M et al. (2007) Breakfast habits affect overall nutrient profiles in adolescents. Public Health Nutr 10, 413-421.

54. Timlin MT, Pereira MA, Story M et al. (2008) Breakfast eating and weight change in a 5 -year prospective analysis of adolescents: Project EAT (Eating Among Teens). Pediatrics 121, E638-E645.

55. Affenito SG (2007) Breakfast: a missed opportunity. J Am Diet Assoc 107, 565-569.

56. Rampersaud GC, Pereira MA, Girard BL et al. (2005) Breakfast habits, nutritional status, body weight, and academic performance in children and adolescents. $J \mathrm{Am}$ Diet Assoc 105, 743-760.

57. Gillman MW, Rifas-Shiman SL, Frazier AL et al. (2000) Family dinner and diet quality among older children and adolescents. Arch Fam Med 9, 235-240.

58. Videon TM \& Manning CK (2003) Influences on adolescent eating patterns: the importance of family meals. $J$ Adolesc Health 32, 365-373.

59. Haapalahti M, Mykkanen H, Tikkanen S et al. (2003) Meal patterns and food use in 10- to 11-year-old Finnish children. Public Health Nutr 6, 365-370.

60. Neumark-Sztainer D, Hannan PJ, Story M et al. (2003) Family meal patterns: associations with sociodemographic characteristics and improved dietary intake among adolescents. J Am Diet Assoc 103, 317-322.

61. Neumark-Sztainer D, Wall M, Story M et al. (2004) Are family meal patterns associated with disordered eating behaviors among adolescents? J Adolesc Health 35, 350-359.

62. Kelsey KS, Campbell MK \& Vanata DF (1998) Parent and adolescent girls' preferences for parental involvement in adolescent health promotion programs. J Am Diet Assoc 98, 906-907. 
63. Neumark-Sztainer D, Story M, Perry C et al. (1999) Factors influencing food choices of adolescents: findings from focus-group discussions with adolescents. J Am Diet Assoc 99, 929-937.

64. Neumark-Sztainer D, Eisenberg M, Fulkerson JA et al. (2008) Family meals and disordered eating in adolescents: longitudinal findings from Project EAT. Arch Pediatr Adolesc Med 162, 17-22.

65. Roth-Isigkeit A, Thyen U, Stöven $\mathrm{H}$ et al. (2005) Pain among children and adolescents: restrictions in daily living and triggering factors. Pediatrics 115, 152-162.

66. Campo J, Comer D, Jansen-McWilliams L et al. (2002) Recurrent pain, emotional distress, and health service use in childhood. J Pediatr 141, 76-83.

67. Campo J, Jansen-McWilliams L, Comer D et al. (1999) Somatization in pediatric primary care: association with psychopathology, functional impairment and use of services. J Am Acad Child Adolesc Psychiatry 38, 1093-1101.

68. Viner R \& Christie D (2005) Fatigue and somatic symptoms. BMJ 330, 1012-1015.

69. Kelly AM, Wall M, Eisenberg ME et al. (2005) Adolescent girls with high body satisfaction: who are they and what can they teach us? J Adolesc Health 37, 391-396.

70. Stice E \& Shaw HE (2002) Role of body dissatisfaction in the onset and maintenance of eating pathology: a synthesis of research findings. J Psychosom Res 53, 985-993.

71. Groesz LM, Levine MP \& Murnen SK (2002) The effect of experimental presentation of thin media images on body satisfaction: a meta-analytic review. Int J Eat Disord 31, $1-16$.
72. Sypeck MF, Gray JJ \& Ahrens AH (2004) No longer just a pretty face: fashion magazines' depictions of ideal female beauty from 1959 to 1999. Int J Eat Disord 36, 342-347.

73. Field AE, Austin SB, Camargo CA Jr et al. (2005) Exposure to the mass media, body shape concerns, and use of supplements to improve weight and shape among male and female adolescents. Pediatrics 116, E214-E220.

74. Byely L, Archibald AB, Graber J et al. (2000) A prospective study of familial and social influences on girls' body image and dieting. Int J Eat Disord 28, 155-164.

75. Eisenberg ME, Neumark-Sztainer D, Story M et al. (2005) The role of social norms and friends' influences on unhealthy weight-control behaviors among adolescent girls. Soc Sci Med 60, 1165-1173.

76. Presnell K, Bearman SK \& Stice E (2004) Risk factors for body dissatisfaction in adolescent boys and girls: a prospective study. Int J Eat Disord 36, 389-401.

77. Field AE, Camargo CA Jr, Taylor CB et al. (2001) Peer, parent, and media influences on the development of weight concerns and frequent dieting among preadolescent and adolescent girls and boys. Pediatrics 107 54-60.

78. Connor Gorber S, Tremblay M, Moher D et al. (2007) A comparison of direct vs. self-report reasures for assessing height, weight and body mass index: a systematic review. Obes Res $\mathbf{8}, 307-326$.

79. Himes JH, Hannan P, Wall M et al. (2005) Factors associated with errors in self-reports of stature, weight, and body mass index in Minnesota adolescents. Ann Epidemiol 15, 272-278. 